\section{EPIDEMIC BRONCHIOLITIS IN INFANTS}

BY

M. E. DISNEY, M.D., M.R.C.P.

Consultant Paediatrician

B. R. SANDIFORD, M.D.

Director, Public Health Laboratory

JOHN CRAGG, M.D., B.Sc., D.P.H., Dip.Bact. Senior Registrar (Pathology)

AND

JLL WOLFF, M.B., Ch.B.

Part-time Clinical Assistant (Research)

From Dudley Road Hospital, Birmingham, and the Virological Section of the Public Health Laboratory, Birmingham

Many good descriptions of epidemic bronchiolitis in infants (Hubble and Osborn, 1941; Garrow and Fawcett, 1953; Heycock and Noble, 1956) have appeared in recent years. Further articles on therapy by Morrison (1955) and by High (1957) have shown how the best modern treatment can decrease the mortality to $1 \%$. However, its frequent very severe and sudden onset, especially in some of the younger infants; and its wide incidence still cause the death of many of these babies. In spite of advances so far made, it is true to say that we are still ignorant of the amount and frequency of secondary bacterial infection, the exact cause of death, and the cause of the condition itself.

With these points in mind we decided to investigate two epidemics occurring in Birmingham in the winters of 1955-6 and 1956-7. In these, a total of 325 infants (under 2 years of age) were admitted to Dudley Road Hospital with acute epidemic bronchiolitis. The first epidemic started in late October, 1955, and continued until early March, 1956. Of the 147 patients admitted, $26.6 \%$ required oxygen therapy and $2.7 \%$ died. The second epidemic started in December, 1956, with a peak in February, 1957. A total of 178 patients were admitted, of whom $44.3 \%$ required oxygen therapy and $5 \%$ died (see Chart).

Clinically the cases did not differ from those described by Hubble and Osborn (1941) and Heycock and Noble (1956). The majority presented as an upper respiratory

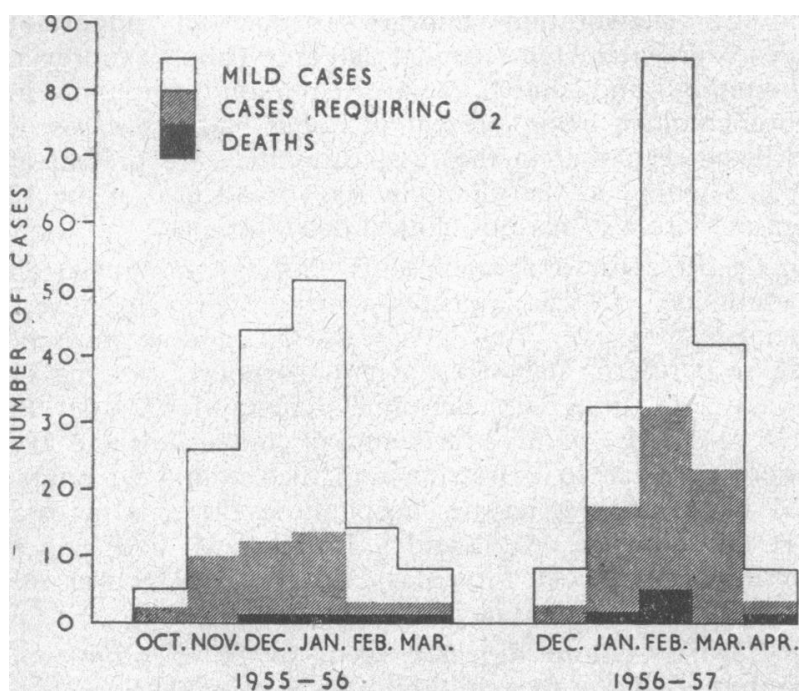

Charts of two outbreaks of epidemic bronchiolitis which occurred in Birmingham in the winter of $1955-6$ and 1956-7. infection, followed by signs of acute respiratory distress and diffuse crepitations, usually in both lungs, some showing gross emphysema and signs of bronchiolar obstruction and high-pitched rhonchi.

A case which on admission was very mild could develop severe respiratory distress in a matter of hours, and rapidly collapse and become moribund. Those which needed oxygen during the course of the illness were classified as severe, and of our 325 cases 118 $(36 \%)$ were considered to be in this category. Morrison et al. (1957) try to separate bronchiolitis and bronchopneumonia, partly on $x$-ray findings and on response to antibiotics. We do not believe this to be possible. Radiologically our cases showed very mixed pictures, though clinically they were identical. $X$-ray appearances gave the following percentages:

Emphysema and patcby consolidation and collapse Normal .

Emphysema only

Consolidation only

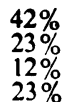

We would agree with Heycock and Noble (1956), who suggest that, excluding staphylococcal pneumonia, bronchiolitis and bronchopneumonia are synonymous in the young infant.

\section{Secondary Bacterial Infection}

Before sulphonamides and antibiotics were available to treat these cases of bronchopneumonia in infants, many different organisms were cultured at post-mortem examination, but their significance is difficult to assess. Perhaps the most important comment at that time was the one found in many text-books-" that empyema was rare in this age-group." Chaplin (1947), writing on empyemata in children, noted that in the 1934-8 series nearly two-thirds occurred in children over the age of 2 . This is in spite of the fact that the vast majority of lower respiratory infections occur in the younger age-group. Even to-day, evidence of secondary bacterial infection (excluding staphylococcal pneumonia) is based on rather flimsy evidence such as leucocyte counts, $x$-ray findings, and response to antibiotics.

We attempted to tackle the problem both bacteriologically and clinically - the former by bacteriological examination of cough swabs from children on admission and just before discharge, and of post-mortem specimens in fatal cases, and the latter by comparing a group of these infants placed on antibiotics or sulphonamides with a group on no such drugs.

We felt justified in this experiment, since previous investigators have assessed the antibacterial agents either as being very important (Hubble and Osborn, 1941 ; Garrow and Fawcett, 1953 ; Heycock and Noble, 1956 ; Morrison et al., 1957) or as probably having no effect (High, 1957).

We therefore divided the cases into different treatment groups, reserving the right to change the treatment if we felt it necessary. Cases were admitted to four different wards, each of three using a different antibacterial drug; in the fourth ward no antibiotics were given. It was felt that, though the groups were not strictly comparable, the investigation might give some useful information. Table I shows results and mortality in these groups.

There are several difficulties in assessing these results. First, eight of the deaths occurred less than 48 hours after admission, so that the antibiotics could have had little chance to take effect. The groups were unequal, both in total numbers and in the percentage of severe 
TaBle I.-Mortality Rates in Different Treatment Groups

\begin{tabular}{|c|c|c|c|c|c|}
\hline Therapy & $\begin{array}{l}\text { Total } \\
\text { No. } \\
\text { of } \\
\text { Cases }\end{array}$ & $\begin{array}{c}\text { Cases } \\
\text { Requiring } \\
\text { Oxygen }\end{array}$ & Deaths & $\begin{array}{c}\text { Total } \\
\text { Mortal- } \\
\text { ity }\end{array}$ & $\begin{array}{c}\text { Mortality } \\
\text { of Cases } \\
\text { Requiring } \\
\text { Oxygen }\end{array}$ \\
\hline $\begin{array}{l}\text { No antibiotics } \\
\text { Sulphonamides } \\
\text { Penicillin } \\
\text { Oxytetracycline } \\
\text { Mixed therapy }\end{array}$ & $\begin{array}{r}123 \\
72 \\
58 \\
49 \\
23\end{array}$ & $\begin{array}{l}34(27 \cdot 6 \%) \\
15(20 \cdot 8 \%) \\
13(22 \cdot 4 \%) \\
41(83 \cdot 7 \%) \\
15(65 \cdot 2 \%)\end{array}$ & $\begin{array}{l}1 \text { T.G.* } \\
2 \text { R.K.*,J.F.* } \\
1 \text { A.M.* } \\
2 \text { R.S., L.W.* } \\
7 \text { R.H., M.N., } \\
\text { S.J., S.M., } \\
\text { D.F.*, C.P.*, } \\
\text { L.B.** }\end{array}$ & $\begin{array}{l}0.8 \% \\
2.7 \% \\
1.7 \% \\
4.0 \% \\
31.7 \%\end{array}$ & $\begin{array}{r}2.9 \% \\
13 \cdot 3 \% \\
7 \cdot 6 \% \\
4.8 \% \\
46 \cdot 6 \%\end{array}$ \\
\hline Total & 325 & $118(36 \cdot 1 \%)$ & 13 & $4.0 \%$ & $11 \cdot 0 \%$ \\
\hline
\end{tabular}

cases. The majority of deaths occurred in the mixed group - that is, in children who were very ill and rapidly deteriorating-so that we felt impelled either to change the antibiotic or to give more than one, to try to save the child. The mortality would seem to be directly related to the overwhelming nature of the illness, regardless of any antibiotic therapy.

Of 34 children who had no antibiotics and who were ill enough to need oxygen therapy, only one died. Unfortunately, necropsy was not done on this child. The only child who died of advanced staphylococcal pneumonia and empyema (R.S.) had been given oxytetracycline from admission until his death three days later (see Table III).

In addition to treatment by antibiotics, or no drugs, as the case might be, we administered oxygen to babies with anoxia, using the ordinary Oxygenaire infant-type tents, combined with face-mask in very severe cases. In the second epidemic we found a modification of the Queen Charlotte type of tent, in which we cut out a crescent at one end so that the larger babies' feet could protrude-very useful in obtaining a high concentration of oxygen. High humidity was also maintained. Feeding was by gavage in severe cases, and clinical detection of dehydration was followed by the giving of extra fluids, usually by mouth or subcutaneously.

\section{Bacteriology}

Bacterial cultures were made from supralaryngeal cough swabs taken on admission from 87 cases. Another swab was taken from 44 of these children just before discharge from hospital. The swabs were similar to those used by Morrison et al. (1957). Each swab was cultured on blood-agar and "chocolate"-agar plates and incubated overnight at $37^{\circ} \mathrm{C}$. This work was done in the routine hospital laboratory. Table II shows the various cultural patterns.

TABLB II.-Bacteriology of Supralaryngeal Cough Swabs, 1956-7

\begin{tabular}{|c|c|c|c|c|}
\hline \multirow{2}{*}{ Cultural Pattern } & \multicolumn{2}{|c|}{ Admission } & \multicolumn{2}{|c|}{ Discharge } \\
\hline & $\begin{array}{l}\text { No. of } \\
\text { Swabs }\end{array}$ & $\%$ & $\begin{array}{l}\text { No. of } \\
\text { Swabs }\end{array}$ & $\%$ \\
\hline 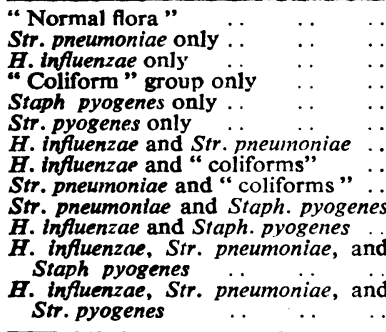 & $\begin{array}{r}16 \\
17 \\
13 \\
9 \\
3 \\
0 \\
10 \\
9 \\
5 \\
3 \\
2 \\
0 \\
0\end{array}$ & $\begin{array}{r}18 \cdot 4 \\
19 \cdot 4 \\
15 \\
10 \cdot 4 \\
3 \cdot 4 \\
\frac{11 \cdot 5}{11 \cdot 4} \\
10 \cdot 4 \\
5 \cdot 8 \\
3 \cdot 4 \\
2 \cdot 3 \\
- \\
-\end{array}$ & $\begin{array}{r}12 \\
11 \\
6 \\
4 \\
1 \\
0 \\
4 \\
2 \\
1 \\
1 \\
0 \\
1 \\
1\end{array}$ & $\begin{array}{l}27.5 \\
25 \\
13 \cdot 2 \\
9.1 \\
2 \cdot 3 \\
9 \cdot 1 \\
4 \cdot 6 \\
2.3 \\
2.3 \\
\end{array}$ \\
\hline Total & 87 & 100 & 44 & 100 \\
\hline
\end{tabular}

" Normal fora" =Str. viridans, $N$. catarrhalis, Staph. albus, and diphtheroids.

Staph. pyogenes, and Str. pyogenes.
Out of the 44 children who had two swabs taken, $75 \%$ showed changing patterns. Only about $50 \%$ of the potentially pathogenic organisms isolated on admission were isolated from the same children on discharge, and, similarly, only about $50 \%$ of those isolated on discharge were present on admission. It was felt that the potentially pathogenic organisms found in the cough swabs were not related to the clinical condition, and that the cultural patterns in any particular child appeared to change regardless of therapy.

\section{Mode and Cause of Death}

A mortality of $64 \%$ in bronchopneumonia was quoted by Still (1915); he thought that age was the most important element in prognosis. The mortality has gradually dropped, first apparently with the introduction of open-air treatment, later by the introduction of oxygen and possibly antibacterial drugs.

Morrison (1955), using a high-concentration oxygen tent in the most severe cases, had only one death in $10 \mathrm{~S}$ cases, and stated that the danger to life was essentially the anoxia from mechanical obstruction. High (1957), with an equally low mortality, emphasizes rehydration and the necessity for extra fluids. Still (1915) stresses the importance of dehydration when he says, "I am inclined to think that the combination of severe diarrhoea with bronchopneumonia, whether the diarrhoea is primary or secondary, makes the prognosis very bad." Hubble and Osborn (1941) mention toxaemia, collapse, shock, and obstructive dyspnoea; while Heycock and Noble (1956) emphasize the degree of tachycardia and that death seemed to be due to right heart failure.

There is little information in the recent literature about the mode of death and its preceding symptoms. Earlier writers mention terminal hyperpyrexia and convulsions as being not uncommon, but other clinical details are usually lacking. While anoxia would appear to be a very important, if not the most important, factor in causing death in these infants, it was felt worth while in view of High's views, backed up by the opinion of such a great clinician as Still, to investigate some of the extrapulmonary features in our fatal cases, with special regard to the factor of dehydration.

Table III is a summary of some of the extrapulmonary features of the fatal cases prior to death (mortality rate $4 \%$ ). Dehydration appears to be an important development in the terminal stages. Though anorexia, vomiting, and diarrhoea are common symptoms in bronchiolitis, being present in about half the cases, it will be seen that in the fatal cases they are present at some period of the illness in $100 \%$, and in 6 of the 13 cases there was obvious clinical dehydration.

Of all cases of bronchiolitis, $75 \%$ are apyrexial on admission, and the majority remain so. Very few have a temperature over $100^{\circ} \mathrm{F}$. $\left(37.8^{\circ} \mathrm{C}\right.$.), and in most of these it returns to normal within 24 hours. Of the 13 fatal cases, nine had a terminal pyrexia of $102-108^{\circ} \mathrm{F}$. $\left(38.9-42.2^{\circ} \mathrm{C}\right.$.).: three of them had convulsions and five were pyrexial on admission and died within 24 hours. M. N., after three days in hospital, developed a pyrexia 48 hours before death, and S. J. and S. M. both had a terminal pyrexia of three days' duration. R. S. was the only one with a definite bacterial infection.

Cardiac failure did not seem to be a prominent feature. Of the five children with a palpable liver, two had associated congenital heart disease. In the others, post-mortem examination did not confirm the apparent 
enlargement, which was probably due to displacement by emphysematous lungs.

The commonest terminal findings in the present series were pyrexia, dehydration, and either collapse or convulsions.

\section{Post-mortem Findings}

The examination was performed as soon as possible after death, this interval being not greater than 24 hours There was fibro-elastosis and an interventricular septal defect in L. W., and an interventricular septal defect in A. M. C. P. and R.S. showed some dilatation of the right ventricle but no other cardiac abnormality. In all other cases the heart and cardiovascular system werc normal. The trachea and main bronchi were congested : thick mucus could be seen in the smaller bronchi and bronchioles. Scattered throughout all lobes were dark reddish-purple unaerated areas and patches of emphysema, and varying degrees of pulmonary oedema. In R. S., in addition to the above picture, there were areas of consolidation and abscesses typical of staphylococcal pneumonia. The liver was enlarged in the two children with congenital heart lesions; in the remainder it was normal in size and pale. The adrenals and other abdominal organs were apparently normal. The brains in all cases were somewhat congested but otherwise normal.
Histology.-After virus specimens and swabs for bacteriology had been taken, the lungs were fixed en bloc in $10 \%$ formol-saline. Haematoxylin-eosin, Gram, Alcian blue, and Lendrum's phloxine tartrazine stains were used on all lung and tracheal tissues, and frozen sections were stained by Sudan IV on some adrenals. The main findings in all cases were mucus plugs within the bronchi or bronchioles, often in both; the epithelium being intact. There was peribronchiolar congestion and "cuffing" of the bronchioles with lymphocytes; alveolar oedema, often with large mononuclears, was a prominent feature. There was a moderate amount of pulmonary collapse and emphysema ; no intranuclear or intracytoplasmic inclusion bodies were seen. In Cases C. P.. R. K., A. M., S. M., and R.S. there was infiltration of the mucus plugs by polymorphs, in addition to the above features. In Cases R. K., A. M., and R. S., Gram-positive cocci, morphologically resembling staphylococci, were seen. There was no evidence of myocarditis or encephalitis, and the adrenals showed no loss of cortical lipoid.

Bacteriology.-A scanty growth of Staph. aureus was obtained from the lungs of C.P. and R.K., in pure culture, and a heavy growth of Staph. aureus from R.S., Staph. albus and C. albicans from L. B., and Staph. albus only from L. W. Cultures were sterile in

TABLE III.-Some of the Clinical Features Particularly Concerning the State of Hydration and Terminal Condition of the Fatal Cases

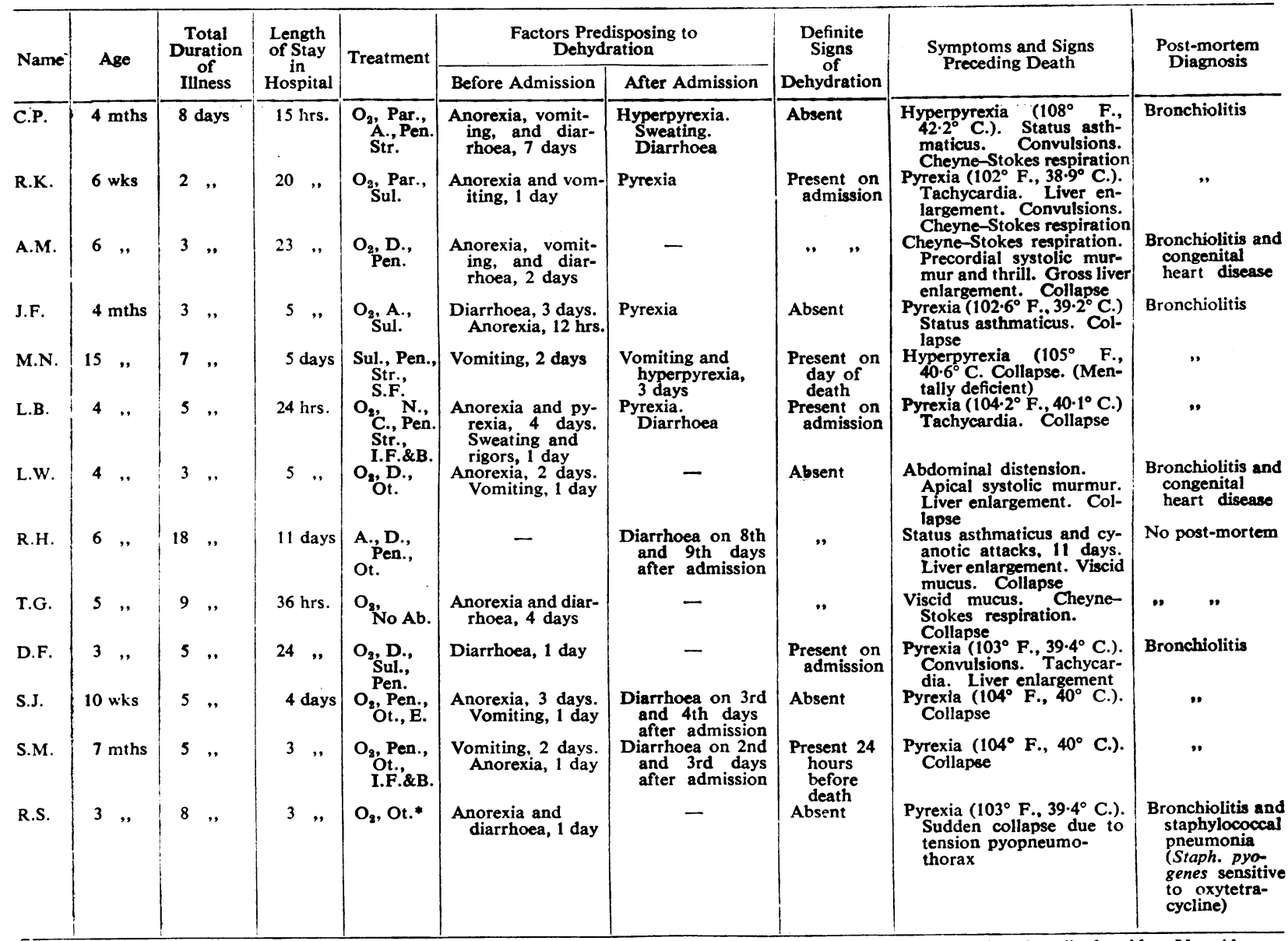

A. = antispasmodics. C. $=$ cortisone. D.=digoxin. E. $=$ erythromycin. I.F.\&B. $=$ intravenous fluids and blood. N. $=$ nikethamide. No Ab. $=$ no antibiotics. $\mathrm{O}_{2}=$ oxygen. Ot. $=$ oxytetracycline. Par. $=$ paraldehyde. Pen. $=$ penicilin. Str. =streptomycin. Sul. = sulphadimidine. S.F. = subcutaneous fuids.

Also drainage with underwater seal for pyopneumothorax.

Note All these patients were restless and dyspnoeic except M.N., who had a terminal collapse unpreceded by dyspnoea. "Collapse" refers to a state in which a baby suddenly becomes pale and hypotonic, develops shallow, irregular, or gasping respirations, and makes no response to external stimuli. 
A. M., J. F., and S. M. No bacteriology was done in the other cases.

Virology.-No virological examinations were done on D. F., S. J., S. M., and R. S. Post-mortem material from the other cases gave negative results in cultures.

\section{Virological Investigations}

During the winter of 1956-7, throat swabs, paired sera, faeces, and lung juices aspirated by syringe (Disney et al., 1956) were collected from 73 patients. From eight fatal cases lung tissue or lung juice and tracheal secretion were obtained.

Cultural examinations for viruses were carried out in the amniotic cavities of chick embryos and monolayer cultures of HeLa, monkey kidney, and human amnion cells. Complement-fixation tests were done on the sera for the presence of antibodies to influenza A, B, and $C$, para-influenza $I$, psittacosis-lymphogranuloma venereum, $Q$ fever, and adenoviruses. Some were also tried against para-influenza II and III antigens. Neutralization tests against adenovirus type I were also used.

Evidence of adenovirus infection was obtained in 8 of the 73 cases-by culture in 6 and serologically in 2 . No virus, however, was isolated from the post-mortem material.

A fuller account of the virological work will be published elsewhere.

\section{Discussion}

The aetiology of epidemic bronchiolitis remains obscure. A large proportion of cases give a history of contact with infection of the upper respiratory tract in other members of the family group. The disease, which is of epidemic nature, may start in early or late winter and usually lasts three to four months, rather resembling outbreaks of influenza. These facts suggest a viral aetiology. Our failure to find a specific virus may be due to inappropriate cultural techniques, the taking of swabs too late in the disease, or a combination of factors. Possibly members of the "cold" group of viruses are responsible. The incidence of bacterial infection in the non-fatal cases is difficult to assess. In our series, Staph. aureus was isolated from 3 out of 11 cases at necropsy, though only one of these had a true staphylococcal pneumonia. No other pathogenic bacteria were isolated from the lungs. This suggests that bacterial pneumonia is a relatively uncommon cause of death. The results of treatment with different antibiotics suggest that they are not very helpful, and because of side-effects they may be dangerous. Possibly oxytetracycline was responsible for the diarrhoea in Cases R. H., S. J., and S. M. (Table III).

The symptoms of bronchiolitis appear to be due to blocking of the smaller bronchi and the bronchioles with plugs of mucus, probably resulting from over-production by the mucous glands due to irritation by a virus. This mucus either remains in the bronchi or is sucked down by respiratory movement and gravity into the bronchioles. Alveolar oedema, so often present, is probably produced by irritation, as also is the interstitial inflammatory reaction. The pulmonary oedema may be caused by anoxia of the pulmonary epithelium, due to bronchiolar blockage (Drinker, 1945); partial collapse of the lung tissue may also result from this cause. Emphysema is a common feature, though the method of its causation is not known for certain; it may be compensatory, or may arise from ball-valve action of the mucus plug (Jackson and Jackson, 1934)-probably both mechanisms are involved.

In our fatal cases the obstruction of the bronchioles by mucus would support the view of Morrison (1955), who thinks that anoxia due to mechanical obstruction is the most important factor in causing death. Table III suggests that many of these babies suffer from some degree of dehydration, from causes such as anorexia, vomiting, diarrhoea, hyperpnoea, tachypnoea, sweating, and difficulty in feeding. It is possible that dehydration produces some adverse change in the mucus.

Harrison and Finberg (1959), writing of hypernatraemic dehydration, say that infants can lose $10-15 \%$ of their water content without classical signs of dehydration, and that a clinical history is more helpful than clinical findings. They go on to say that " fever is commonly associated with hypernatraemia and may be both a predisposing factor and a manifestation of this state." Manifestations in the central nervous system can include lethargy, coma, hyperirritability, tremors, and convulsions.

All the symptoms which preceded death may be explained by anoxia, possibly combined with dehydration; recent clinical experience in the 1958-9 epidemic tends to support this possible explanation. In two severe cases the patients, who were pink and contented in the newest type of Oxygenaire high-concentration tents, developed gastro-enteritis leading to sudden severe dehydration. They became grossly cyanosed and restless, and died in a few hours. ( $E$. coli O. 119 was isolated after death from one case.)

Gastaut and Gastaut (1958) have suggested that many of the so-called essential hyperthermic, and even afebrile, convulsions in infancy and childhood are due to anoxia.

Obviously, further studies on this disease are necessary. We would like to suggest that the possibility of dehydration should always be considered, especially in the more severe cases, and that the treatment of anoxia, with the replacement of fluid, is probably much more important than the administration of any particular antibiotic, which in itself may carry dangers.

As Garrod and Scowen (1960) so aptly remark. "It would be unwise to attempt the definition of hard and fast rules about conditions for which antibiotic treatment is justified." Recent opinion suggests that the prevention of bacteriological complications in generalized virus infections by use of antibiotics is of doubtful value-primarily because no antibiotic has a sufficiently broad spectrum to protect against all potential invaders and may quickly produce a floral change to more resistant types (Bywaters, 1960).

We hesitate to give advice on the administration of antibiotics in this condition. Our present practice is to give an antibiotic, or combination of antibiotics, only when there is reason to suspect staphylococcal pneumonia, or in the few cases which are so severe that the supervention of a bacterial infection might prove fatal.

\section{Summary}

Two outbreaks of epidemic bronchiolitis in Birmingham in 1955-6 and 1956-7 were studied.

A comparison of antibiotics in treatment was made.

The terminal symptoms and post-mortem appearances in fatal cases are described. 
The virological investigations on $\mathbf{7 4}$ cases are briefly noted.

The possible causes of death and their prevention are discussed.

We are grateful to the nursing and resident medical staff of the paediatric department of Dudley Road Hospital, without whose help this investigation would not have been possible. We wish to acknowledge the technical assistance of Mr. A. J. Higgs, F.I.M.L.T., and Mr. L. Westwood, A.I.M.L.T. We are also indebted to Dr. J. C. Cole, consulting radiologist, Dudley Road Hospital, for help in interpreting the chest $x$-ray films.

\section{REFERENCES}

Bywaters, E. G. L. (1960). Brit. med. Bull., 16, 47

Chaplin, A. E. (1947). Arch. Dis. Childh., 22, 91.

Disney, M. E., Wolff, J., and Wood, B. S. B. (1956). Lancet 1,767 .

Drinker, C. K. (1945). Pulmonary Edema and Inflammation. Harvard Univ Press, Cambridge, Mass.

Garrod, L. P., and Scowen, E. F. (1960). Brit. med. Bull., 16, 23.

Garrow, D. H., and Fawcett, J. W. (1953). Lancet, 2, 795

Gastaut, H., and Gastaut, Y.'(1958). Electroenceph. clin. Neurophysiol., 10, 607

Harrison, H. E., and Finberg, L. (1959). Pediat. Clin. N. Amer. 6. 193 .

Heycock, J. B., and Noble, T. C. (1956). Brit. med. J., 1, 438

High, R. H. (1957). Pediat. clin. N. Amer., 4, 183.

Hubble, D., and Osborn, G. R. (1941). Brit. med. J., 1, 107

Jackson C., and Jackson, C L. (1934). Bronchoscopy, Esophagoscopy and Gastroscopy, 3rd ed. Saunders, Philadelphia. Morrison, B. (1955) Lancet, 2, 737.

- Bass, D, Davis, J. A., Hobson, D., Madsen, T. I., and Masters, P. L. (1957). İbid., 2, 1077.

Still, G. F. (1915). Common Disorders and Diseases of Childhood, 3rd ed., p. 367. Oxford Medical Publications, London.

\section{Medical Memoranda}

\section{Metastatic Carcinoma at the Site of Injection of Iron-dextran Complex}

Carcinomatous metastases sometimes occur in injured or inflamed tissue (Willis, 1952). Such metastases are, however, very rare, so that the finding of one at the site of an intramuscular injection of iron-dextran complex ("imferon ") is of some interest, the more so since this preparation has been shown to be carcinogenic in rats (Richmond, 1959), and this observation was confirmed and extended by Haddow and Horning (1960) in rats and mice.

\section{CASE History}

On July 15, 1958, a woman aged 37 was admitted to hospital complaining of offensive vaginal discharge and bearing-down pain present for six weeks, with fairly heavy bleeding for two days before admission.

On examination she was found to have a carcinoma of the cervix, stage II, involving the posterior and left lateral cervix and extending posteriorly to the vault. Lateral fornices and parametria were not clinically involved. Blood picture: $\mathrm{Hb}, 71 \%$; W.B.C., 8,500/c.mm.

After consultation between gynaecologist and radiotherapist it was decided to give a full dose of intracavitary radium followed by a Wertheim hysterectomy. On July 29 she had her first radium insertion, followed two weeks later by a second insertion. At this stage a blood examination showed that her haemoglobin had dropped to $65 \%$, and on August 15 a course of iron-dextran was started. After a test dose of $2 \mathrm{ml}$. she was given $5 \mathrm{ml}$. on alternate days for five doses. On August 19 she had her third radium insertion, which was removed after four and a half hours because of continuous pyrexia. On September 4, 16 days after her course of radium had finished, a Wertheim hysterectomy was performed, and two weeks later a second course of irondextran was begun; this was similar to the first. On

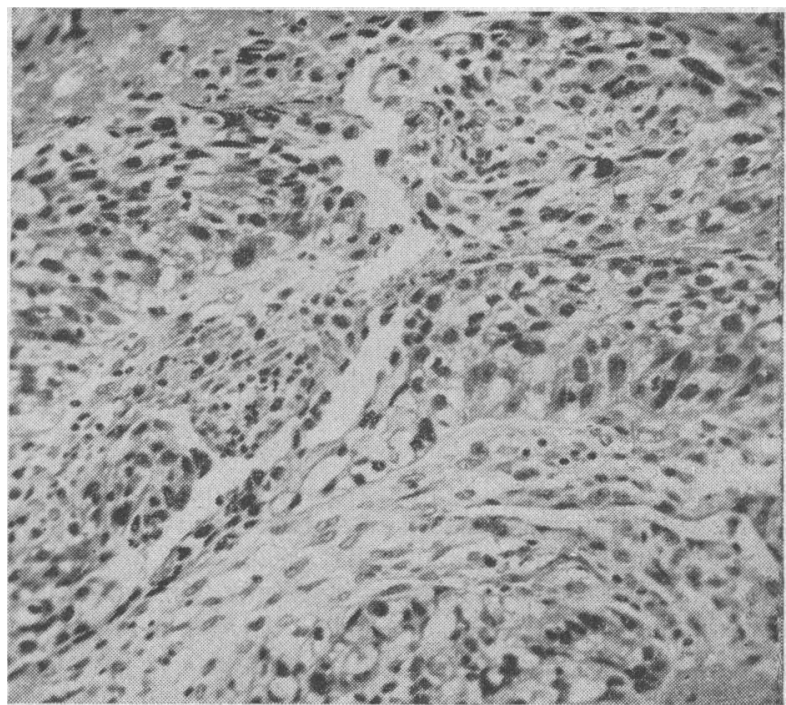

FIG. 1.-Original squamous-cell carcinoma of the cervix. (H. and E. $\times 170$.

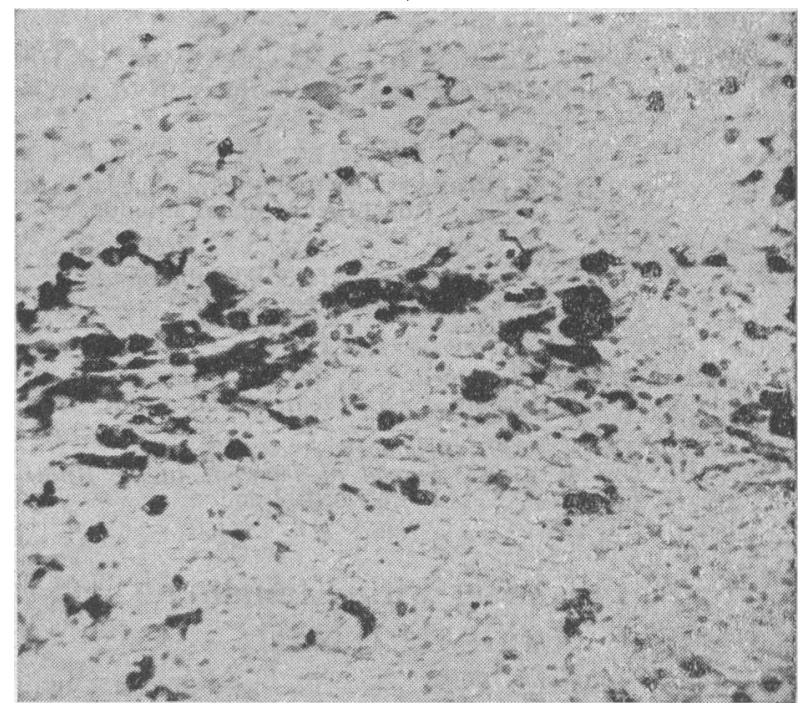

FIG. 2.-Iron-laden histiocytes and tumour at injection site. (Perls's iron. $\times 170$.)

October 15 she was found to have a recurrent mass in the left side of the pelvis, for which she had a course of $x$-ray therapy.

Eight weeks after her hysterectomy, when seen in the follow-up clinic, the patient complained of a red painful area in the right gluteal region at the site of her previous injections, and on examination the skin over the right gluteal region was red, tender, and indurated for an area $8 \mathrm{~cm}$. in diameter. Per vaginam, the mass in the left iliac fossa had not altered in size since treatment. The right side of the pelvis was clear of any evidence of growth. She was readmitted to hospital, and exploration of the swelling in the right buttock showed grey necrotic tissue which microscopically proved to be poorly differentiated squamous carcinoma. A course of palliative $x$-ray therapy to the right buttock produced slight temporary shrinkage, but eventually a hindquarter amputation was necessary. One month later she developed metastases in the lungs, together with local recurrence in the wound, and died on February 29, 1960, two months after the amputation.

Histological Findings.-The first biopsy of the cervix showed a rather anaplastic squamous-cell carcinoma (Fig. 1). When the uterus was removed, parts of the tumour were viable, but no local spread or lymph-node metastases were found. The lesion in the right buttock which was 